\title{
Analisa Kebutuhan Latihan Fisik Pemain Sepakbola Dalam Kompetisi AFF U-19 (Studi Analisis Terhadap Pemain Gelandang Timnas Indonesia U-19)
}

\author{
Anwarul Hidayat ${ }^{\bowtie}$, Iman Imanudin, Surdiniaty Ugelta \\ Program Studi Ilmu Keolahragaan, Fakultas Pendidikan Olahraga dan Kesehatan, \\ Universitas Pendidikan Indonesia, Indonesia
}

\begin{abstract}
Abstrak
Penelitian ini bertujuan untuk mengetahui berapa kebutuhan latihan fisik pemain sepakbola dalam kompetisi AFF U-19 melalui metode analisis pertandingan. Penelitian ini merupakan penelitian yang dilaksanakan pada atlet Indonesia yang berposisi sebagai gelandang. Jumlah sample pada penelitian ini sebanyak 1 orang atlet yang telah berhasil menyumbangkan medali emas pada kompetisi aff u-19 tahun 2013 yaitu evan dimas darmono. Teknik penarikan sample menggunakan cara purposive sampling yang mana peneliti mengambil orang-orang yang terpilih menurut ciri-ciri spesifik yang dimiliki oleh sampel itu berdasarkan kebutuhan penelitian. Instrumen penelitian yang digunakan adalah observasi sistematis, pengambilan data untuk penelitian ini dilakukan dengan sebuah analisa, sedangkan untuk analisis data penelitian ini menggunakan sign system sebagai instrumen pengamatan kejadian yang muncul berkali-kali. Observer men-tally kejadian yang muncul di video ke dalam scoring sheet yang dibuat oleh peneliti. Berdasarkan hasil analisis diperoleh kebutuhan fisik yang berbeda- beda. untuk latihan daya tahan otot $55,00 \%$, kecepatan $14,00 \%$, power $14,00 \%$, kelincahan $14,00 \%$, kekuatan tungkai $1,15 \%$, kekuatan otot perut $1,50 \%$. Dengan demikian kesimpulan dari hasil penelitian ini kebutuhan latihan fisik dapat dihitung dengan menganalisis video pertandingan (game analysis). Disarankan kepada pelatih, pengajar, pembina olahrga dan para pmbaca agar melakukan game analisis untuk mengetahui kebutuhan latihan fisik agar latihan lebih efektif dan efesien.
\end{abstract}

Kata Kunci:

Kompetisi, Latihan, Fisik, Sepakbola

\begin{abstract}
This study aims to determine how much physical training needs of soccer players in the AFF U-19 competition through the match analysis method. This research is a research conducted on Indonesian athletes who are positioned as a midfielder. The number of samples in this study were 1 athlete who had succeeded in donating a gold medal in the 2013 U-19 competition, namely Evan dimas Darmono. The sampling technique uses a purposive sampling method in which researchers take selected people according to the specific characteristics possessed by the sample based on research needs. The research instrument used was systematic observation, data retrieval for this study was carried out with an analysis, whereas for the analysis of the data this study used a sign system as an instrument for observing events that appeared
\end{abstract}


repeatedly. The observer tally the events that appear on the video into the scoring sheet made by the researcher. Based on the analysis results obtained by different physical needs. to exercise muscle endurance $55.00 \%$, speed $14.00 \%$, power $14.00 \%$, agility $14.00 \%$, leg strength $1.15 \%$, abdominal strength $1.50 \%$. Thus the conclusions from the results of this study the need for physical exercise can be calculated by analyzing the game video (game analysis). It is recommended that trainers, instructors, sports coaches and readers read analytical games to determine the need for physical training to make training more effective and efficient.

(C) 2019 Universitas Pendidikan Indonesia

Universitas Pendidikan Indonesia, J1. Dr. Setiabudhi No. 299 Bandung

E-mail: awayhidayat@gmail.com 


\section{PENDAHULUAN}

Sepakbola merupakan olahraga yang dinamis dan menuntut kesiapan fisik yang prima dengan dukungan teknik, taktik dan mental yang baik. Pergerakan pemain dalam pertandingan, baik dengan bola maupun tanpa bola sangat tepat dan dengan berlari sangat cepat dan dengan berlari mencari celah-celah daerah yang dapat diterobos untuk memasukkan bola ke gawang. Kondis ini berlangsung dalam waktu yang cukup lama, sehingga begitu menguras energi dan menyebabkan kelelahan. Dengan demikian, seorang pemain sepakbola harus melakukan latihan fisik dengan baik untuk menunjang kemampuan kondisi tubuhnya selama pertandingan berlangsung.

Cabang olahraga sepakbola merupakan olahraga yang banyak diminati oleh masyarakat di dunia, termasuk masyarakat Indonesia. dalam peningkatan kecakapan dalam sepakbola, keterampilan dasar sepakbola erat sekali hubungannya dengan kordinasi gerak. Dalam bermain sepakbola harus paham dan mengetahui teknik dasar yang benar, disamping itu faktor yang paling menunjang dalam meraih prestasi adalah faktor kondisi fisik.

Untuk mencapai prestasi yang tinggi dengan melakukan latihan harus pula mengetahui dan menguasai aspek-aspek yang perlu diperhtikan dan dilatih secara seksama oleh atlet yaitu : latihan fisik, latihan teknik, latihan taktik dan latihan mental. Seseorang dalam kondisi fisik yang baik apabila ia mempunyai kesanggupan untuk melakukan kegiatan fisik tanpa mengalami kelelahan yang berlebihan (Harsono \& Drs, 1988).

Piala AFF merupakan ajang sepak bola paling bergengsi di Asia Tenggara. Turnamen dua tahunan ini menjadi panggung bagi 11 negara untuk unjuk kebolehan sekaligus menjadi yang terbaik di Asia Tenggara. Piala AFF pertama kali diselenggarakan pada tahun 1996 di Singapura dengan nama awal Piala Tiger. Pemakaian nama Piala Tiger tidak terlepas dari sponsor utama, yakni perusahaan bir asal Singapura, Tiger Beer. Di kancah Asia Tenggara sekalipun, Indonesia belum pernah berhasil menjadi juara Piala AFF (dulu disebut sebagai Piala Tiger) dan hanya menjadi salah satu tim unggulan. Prestasi tertinggi Indonesia hanyalah tempat kedua pada tahun 2000, 2002, 2004, 2010, dan 2016 sehingga menjadikan Indonesia negara terbanyak peraih runner-up dari seluruh negara peserta Piala AFF.
Di ajang SEA Games pun Indonesia jarang meraih medali emas, yang terakhir diraih tahun 1991.

Tim nasional sepak bola U-19 Indonesia adalah tim nasional sepak bola yang berisikan para pemain di bawah usia 19 tahun, yang mewakili Indonesia pada ajang piala AFF. Tim ini berada di bawah kendali Persatuan Sepak Bola Seluruh Indonesia. Dari lima kali tampil, Garuda Jaya pernah satu kali sukses menjadi juara pada tahun 2013 lalu. Ketika itu, tim asuhan Indra Sjafri yang diisi pemain-pemain macam Evan Dimas Darmono dan Ilham Udin Armayn, mengalahkan Vietnam pada laga final yang berlangsung di hadapan pendukung sendiri. Setahun kemudian, timnas U-19 gagal menyamai pencapaian tersebut dan terhenti di fase grup, seperti tiga gelaran sebelumnya tahun 2002, 2005, dan 2011. Tahun lalu, Indonesia batal ikut serta karena masih harus jalani sanksi FIFA. Secara keseluruhan, Piala AFF U-19 sudah digelar 13 kali, dan sejak 2005 dilangsungkan rutin setahun sekali. Thailand merupakan tim paling sukses di ajang ini dengan empat trofi.

Tentunya banyak hal yang perlu di evaluasi dari prestasi yang kurang ini, salah satu usaha untuk meningkatkan prestasi adalah melalui latihan yang sistematis, berulang-ulang dan terukur dengan melibatkan berbagai disiplin ilmu pengetahuan dan teknologi serta penerapan prinsip-prinsip dan aspek-aspek latihan yang meliputi fisik, teknik, taktik, dan mental.

Hasil pengamatan inilah yang mendorong penulis untuk melakukan penelitian dan untuk kepentingan pelatih seperti dalam periodesasi latihan yang direncanakan dalam jangka panjang, mempunyai karakteristik tersendiri, salah satunya spesifikasi latihan teknik, fisik, taktik, dan mental yang mempunyai karakteristik permainan dalam pertandingan yang sebenarnya.

Proses latihan tersebut harus diperhatikan dengan baik supaya pada saat pertandingan atlet sudah siap menghadapi pola permainan dan karakteristik permainan lawan. Dengan demikian, penulis akan menggambarkan jumlah dribbling, passing, shooting, sprint, long-passing, dan heading. Unsur dasar dan kebutuhan khusus dalam suatu permainan sepakbola, dan ditambah dengan non-teknik seperti kecepatan dan reaksi yang dilakukan menjadi rujukan para pelatih dalam menyusun program latihan bagi atletnya, terutama untuk latihan fisik. 


\section{METODE}

Metode yang digunakan dalam penelitian ini adalah metode kuantitatif deskriptif, hal tersebut sesuai dengan apa yang dikemukakan oleh (Arikunto \& Praktik, 2002) sebagai berikut. "peneliti deskriptif ini merupakan penelitian yang benar-benar hanya memaparkan apa yang terdapat atau terjadi dalam sebuah kancah, lapangan, atau wilayah tertentu". Dalam penelitian ini populasi yang diteliti adalah tim wushu taolu, pelatnas Indonesia yang semakin menjadi sorotan publik atas berkembangnya wushu di Tanah Air. Sampel dapat mewakili populasi dengan tujuan peneliti, maka peneliti menentukan untuk pengambilan sampel dengan cara purposive sampling. (Sugianto \& Imanudin, 2017) sampling purposive dilakukan dengan mengambil orang-orang yang terpilih betul oleh peneliti menurut ciri-ciri spesifik yang dimiliki oleh sampel itu Sampel dapat mewakili populasi dengan tujuan peneliti, maka peneliti menentukan untuk pengambilan sampel dengan cara purposive sampling, peneliti mengambil sampel timnas indonesia yang berhasil meraih medali emas pada ajang AFF U-19. Dalam penelitian ini, instrumen yang digunakan adalah observasi sistematis. Menurut (Arikunto \& Praktik, 2002) dalam proses observasi, observer (pengamat) tinggal memberikan tanda pada kolom tempat peristiwa muncul. Itulah sebabnya maka cara bekerja seperti ini disebut sistem tanda (sign system).

\section{HASIL DAN PEMBAHASAN}

Hasil pengolahan dan analisis data kan peneuan sebagai berikut:

Berdasarkan hasil analisis diperoleh kebutuhan fisik yang berbeda- beda dari setiap komponen kondidi fisiknya. Dan untuk latihan daya tahan otot latihan fisik yang paling dominan.

Kebutuhan latihan fisik pemain sepakbola yang berposisi sebagai gelandang dapat dihitung dengan menganalisis apa yang terjadi dilapangan atau biasa disebut game analysis. Dengan demikian kesimpulan dari hasil penelitian ini kebutuhan latihan fisik dapat dihitung dengan menganalisis video pertandingan (game analysis). Disarankan kepada pelatih, pengajar, pembina olahrga dan para pmbaca agar melakukan game analisis untuk mengetahui kebutuhan latihan fisik agar latihan lebih efektif dan efesien.

\section{KESIMPULAN}

Berdasarkan hasil analisis diperoleh kebutuhan fisik yang berbeda- beda. untuk latihan daya tahan otot $55,00 \%$, kecepatan $14,00 \%$, power $14,00 \%$, kelincahan $14,00 \%$, kekuatan tungkai $1,15 \%$, kekuatan otot perut $1,50 \%$.

Kebutuhan latihan fisik pemain sepakbola yang berposisi sebagai gelandang dapat dihitung dengan menganalisis apa yang terjadi dilapangan atau biasa disebut game analysis. \%. Dengan demikian kesimpulan dari hasil penelitian ini kebutuhan latihan fisik dapat dihitung dengan menganalisis video pertandingan (game analysis). Disarankan kepada pelatih, pengajar, pembina olahrga dan para pmbaca agar melakukan game analisis untuk mengetahui kebutuhan latihan fisik agar latihan lebih efektif dan efesien.

\section{DAFTAR PUSTAKA}

Arikunto, S. (2002). Metodologi Penelitian. Rineka cipta. Yogyakarta.

Harsono (1988). Coaching dan Aspek-aspek Psikologis dalam Coaching. Direktorat Jendral Pendidikan Tinggi: Jakarta.

Sugianto, M. P., \& Imanudin, I. (2017). Analisa Kebutuhan Latihan Fisik Cabang Olahraga Wushu Nomor Taolu. Jurnal Terapan Ilmu Keolahragaan, 77-79. 